\title{
Gophers of Yesteryear
}

\author{
By CLIFE SHAW
}

Photos by W. Yanchinski
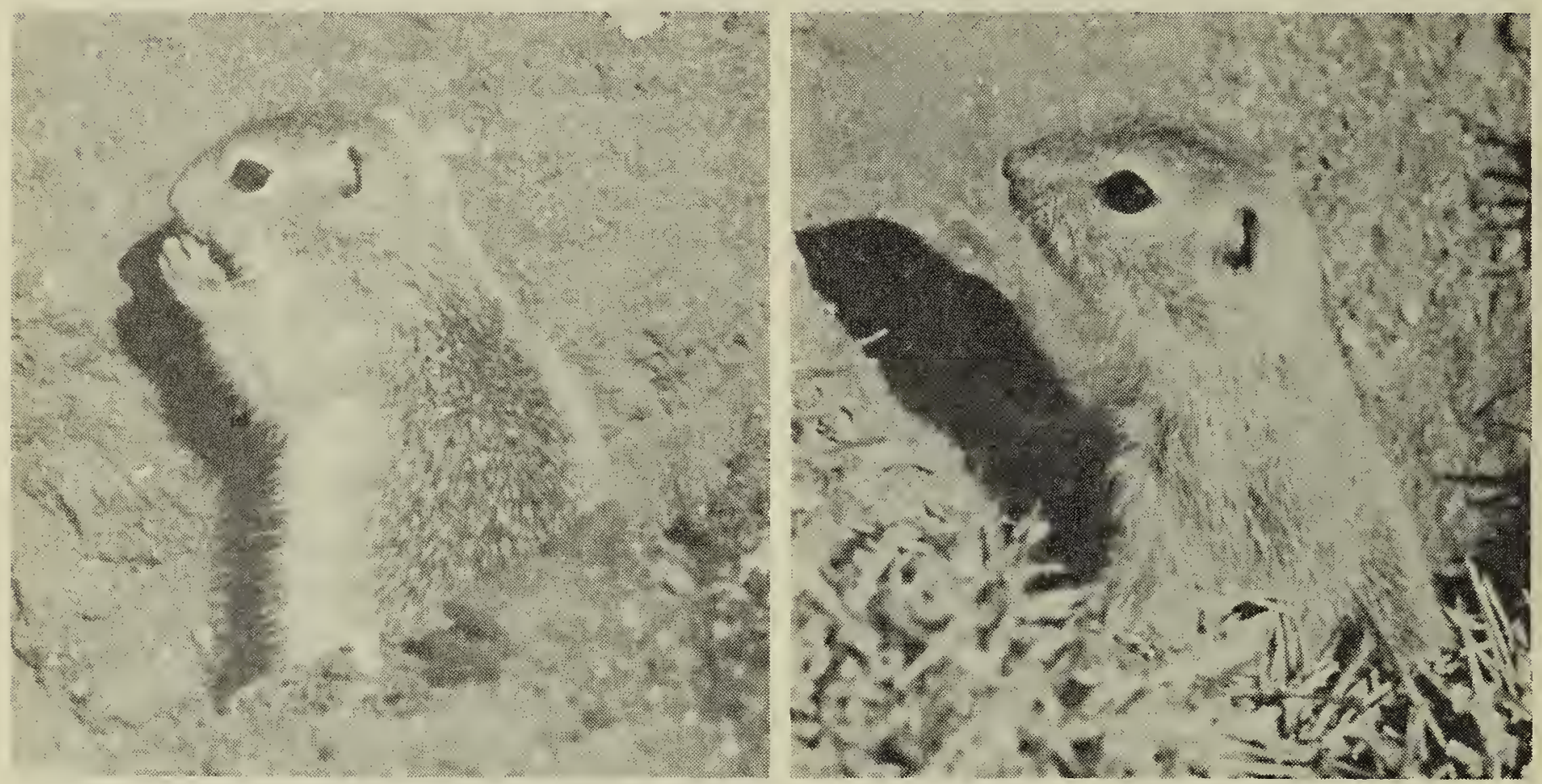

The following is an excerpt from the book of T. W. Wilby, an Englishman, one of the earliest to attempt to cross Canada by automobile, 1912. This refers to the Saskatchewan part of his trip from Moose Jaw to Swift Current.

"The roads were positively alive with yellow gophers. There were score and hundreds of them as far as the eye could reach, and it looked as though progress could only be made over their crushed and mangled remains. They had burrowed under the roadway, and they sat up in the ruts waiting for us. They dared us to run over them. They waited until the rubber wheels were upon them; they turned tail, scampered to a hole in the rut stoodup, put their thumbs to their noses, and turning a somersault, catapulted themselves into their subways. Before the car could say 'Jack Robinson' they would bob up serenely thirty yards away, squeaking derisively".

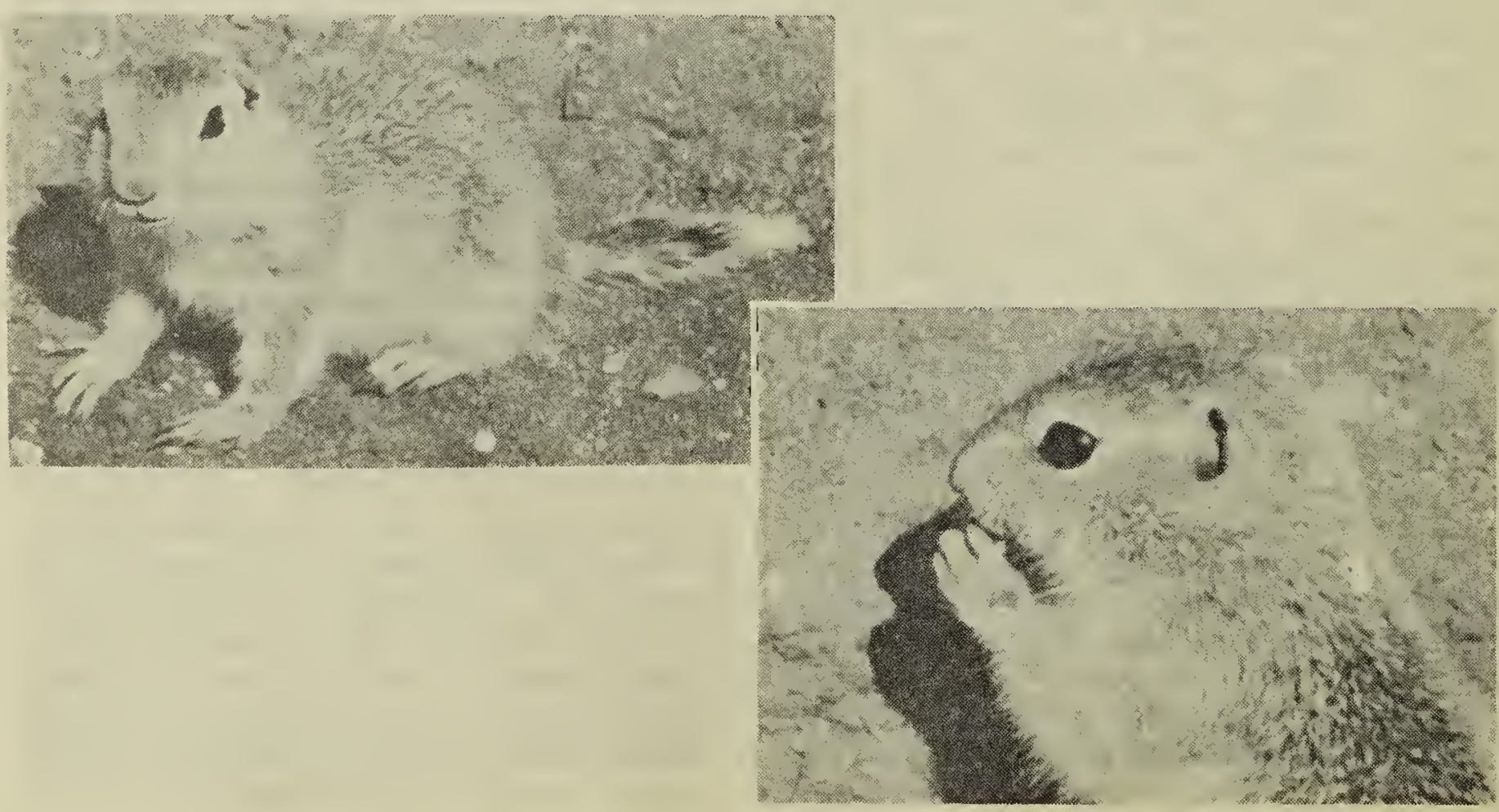

